Correspondence

\title{
Strain-induced dissolution of $\mathrm{Y}-\mathrm{Ti}-\mathrm{O}$ nano-oxides in a consolidated ferritic oxide dispersion strengthened (ODS) steel
}

\author{
B. Hary ${ }^{a, *}$, R. Logé ${ }^{b}$, J. Ribis ${ }^{a}$, M-H. Mathon ${ }^{c}$, M. Van Der Meer ${ }^{b}$, T. Baudin ${ }^{d}$, Y. de Carlan ${ }^{a}$ \\ ${ }^{a}$ DEN-Service de Recherches Métallurgiques Appliquées, CEA, Université Paris-Saclay, F-91191 Gif-sur-Yvette, France \\ ${ }^{\mathrm{b}}$ LMTM, Ecole Polytechnique Fédérale de Lausanne, rue de la Maladière 71b, CH-2002 Neuchâtel, Switzerland \\ ${ }^{\mathrm{c}}$ LLB, CEA, CNRS, Université Paris-Saclay, CEA Saclay, F-91191 Gif-sur-Yvette, France \\ d ICMMO, SP2M, Univ. Paris-Sud, Université Paris-Saclay, UMR CNRS 8182, bât.410, F-91405 Orsay, France
}

\section{A R T I C L E I N F O}

\section{Keywords:}

ODS alloy

Severe plastic deformation

Energy filtered TEM

Small angle neutron scattering

Dissolution

\begin{abstract}
A B S T R A C T
The present study shows the influence of severe plastic deformation on highly stable Y-Ti-O nano-oxides present in ferritic ODS alloys used for nuclear applications. An innovative strain path implying alternated compressions was used to deform the material to an equivalent plastic strain of 13. Energy Filtered Transmission Electron Microscopy and Small Angle Neutron Scattering revealed the strain-induced dissolution of the Y-Ti-O nano-oxides. It appears to be the first time that dissolution of such particles is clearly observed after deformation. Annealing the material enables to re-precipitate the nano-oxides. These results show a strong analogy with the mechanical alloying of ODS powder.
\end{abstract}

\section{Introduction}

Control of the secondary phase precipitation is a key parameter to enhance the manufacturing process of an alloy as well as its mechanical properties. A conventional way to dissolve precipitates is obviously to perform annealing above their equilibrium domain. However, it is known that dissolution [1-3] or phase transformation [4,5] can be strain-induced as well, particularly in Al-Cu alloys [6-8] where coherent particles $\theta^{\prime}$ and $\theta^{\prime \prime}$ are repeatedly sheared by dislocations, leading to their partial or complete dissolution. Strain-induced dissolution also occurs during the manufacturing route of Oxide Dispersion Strengthened (ODS) steels, mainly considered for nuclear applications. Indeed, when elaborating these materials, an yttria $\left(\mathrm{Y}_{2} \mathrm{O}_{3}\right)$ powder is milled with the ferritic matrix powder through the mechanical alloying process leading to the dissolution of yttria particles [9-13]. This phenomenon is regularly observed but the underlying mechanisms are very little commented. Then, nano-oxides precipitate during hot consolidation and give the material its high mechanical properties.

In this study, focus was made on the investigation of strain-induced dissolution of these nano-oxides, present in consolidated ODS alloys. Different types of nano-oxides can precipitate according to the chemical composition of the alloy although in recent ODS steels, Y-Ti-O nanoclusters (average diameter of 2-3 nm) are the most common ones [14-20]. The structure of these precipitates is close to the $\mathrm{Y}_{2} \mathrm{Ti}_{2} \mathrm{O}_{7}$ pyrochlorelike structure. They become more and more stoichiometric with the increase of their size. They usually exhibit a cube-on-cube $[16,17,21]$ or cube-on-edge $[16,20]$ coherency relationship with the ferritic matrix as well as possible misfit dislocations at their interfaces (semi-coherent particles). Many studies [22-26] showed that non-stoichiometric or $\mathrm{Y}_{2} \mathrm{TiO}_{5}$ compounds can also be found. These nanoparticles show a remarkable thermal stability that can be attributed to their complex structure, the very low solubility of yttrium and oxygen in the matrix and the low interfacial energy which reduces the so-called Gibbs-Thomson effect [16]. At very high temperature $\left(>1300^{\circ} \mathrm{C}\right)$, they become more sensitive to Ostwald ripening and coarsen significantly $[23,27,28]$. A recent study [29] reported that plastic deformation can notably affect some ODS particles such as $\mathrm{YAlO}_{3}$ in a PM2000 ODS alloy, that undergo twinning which allow them to sustain a high degree of plastic strain although they are harder than the matrix. Nonetheless, ODS particles are never dissolved, even above the melting point of the matrix, around $1530^{\circ} \mathrm{C}$. Therefore, this singular behavior motivates the investigation of the influence of severe plastic deformation (SPD) on the stability of such nanoparticles. A combination of mechanical and thermal treatments can provide new degrees of freedom in the control of secondary phase precipitation.

\section{Materials and methods}

The chemical composition of the ODS alloy investigated is presented in Table 1. The base powder with a nominal composition of Fe-14Cr-1W (wt $\%$ ) commonly used in the manufacturing of ODS steels was atomized

\footnotetext{
* Corresponding author. Present address: Université Libre de Bruxelles, 50 avenue FD Roosevelt, B1050 Bruxelles, Belgium.

E-mail address: benj.hary@gmail.com (B. Hary).
} 
Table 1

Chemical composition of the as-extruded material.

\begin{tabular}{llllllllll}
\hline Element & $\mathrm{Cr}$ & $\mathrm{W}$ & $\mathrm{Ti}$ & $\mathrm{C}$ & $\mathrm{Ni}$ & $\mathrm{Mn}$ & $\mathrm{Y}$ & $\mathrm{O}$ & $\mathrm{Fe}$ \\
\hline $\mathrm{wt} \%$ & 14,13 & 0,91 & 0,20 & 0,03 & 0,20 & 0,29 & 0,13 & 0,11 & $\mathrm{Bal}$. \\
\hline
\end{tabular}
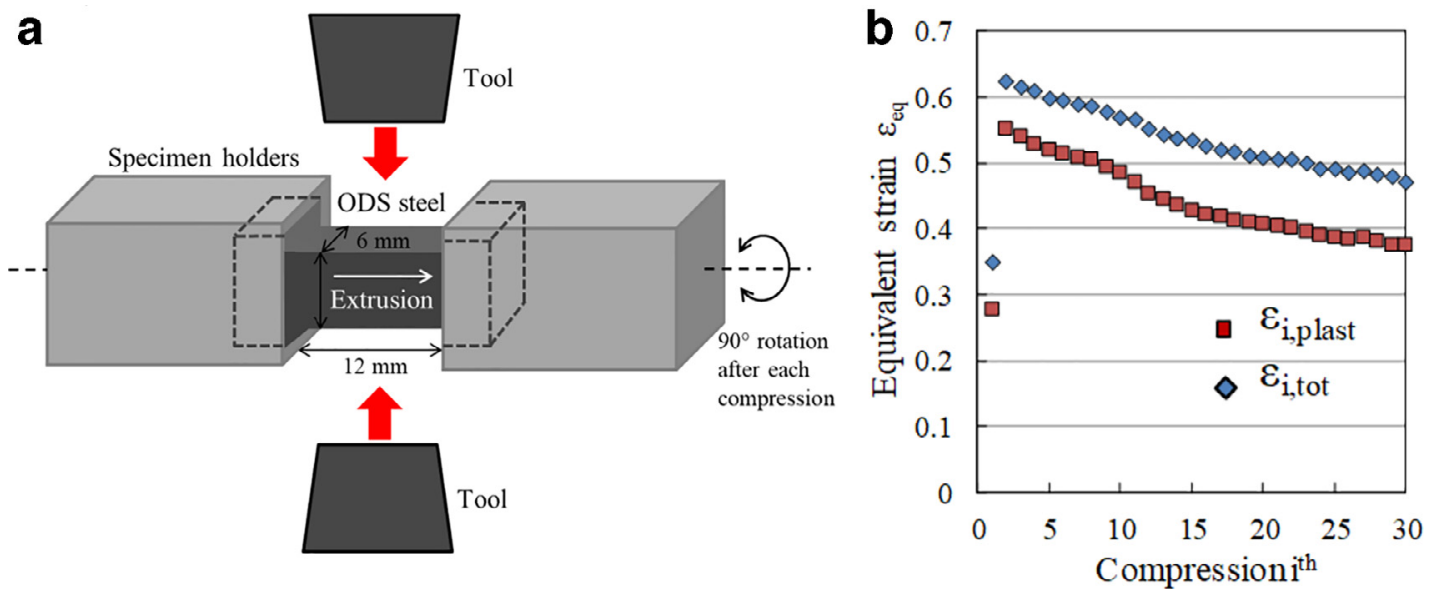

Fig. 1. (a) Principle of the MaxStrain MCU used to perform the SPD, (b) equivalent strain (total and plastic) for each hit during the SPD process.

at Aubert \& Duval. This base powder was milled with a powder of titanium hydride $\left(\mathrm{TiH}_{2}\right)$ and yttria $\left(\mathrm{Y}_{2} \mathrm{O}_{3}\right)$ at CEA in an attritor under argon atmosphere for $10 \mathrm{~h}$ at a speed of 400 rotations per minutes. The ball-to-powder ratio was about to 15 . The proportion of titanium hydride and yttria incorporated was managed in order to target a mass percentage of $0.2 \mathrm{Ti}$ and $0.2 \mathrm{Y}_{2} \mathrm{O}_{3}$ in the consolidated material. The ODS steel powder is put into a soft steel can and pre-compacted during $1 \mathrm{~h}$ at $1100{ }^{\circ} \mathrm{C}$. Then, the material is consolidated by hot extrusion at $1100^{\circ} \mathrm{C}$ with a surface reduction ratio of 13 and air cooled. This is a standard ODS manufacturing route. During the intense grinding phase, the yttrium oxides dissolve and re-precipitate with the titanium to form the Y-Ti-O pyrochlores.

The ODS steel is cold-deformed using the MaxStrain Mobile Conversion Unit (MCU) of a Gleeble ${ }^{\circledR} 3800$ system from Dynamics System Inc. ${ }^{\circledR}$ at EPFL. The MaxStrain MCU enables to perform Severe Plastic Deformation (SPD) by alternated compression along two orthogonal directions (see Fig. 1(a)). First, the specimen is compressed along one direction. Then, the device is rotated by $90^{\circ}$ degree before performing the $2^{\text {nd }}$ compression. After the second compression, the device rotates back to the initial position, the sample undergoes the third compression, and so on. The ODS steel is embedded in two steel specimen holders that prevent deformation along the third direction, which is here the extrusion direction of the material. The test set-up therefore ensures plane strain conditions. The ODS specimen has a square cross section of $6 \times 6 \mathrm{~mm}^{2}$. The equivalent strain $\varepsilon_{\text {eq }}$ and the von Mises equivalent stress are computed from the displacement and load sensors of the Gleeble ${ }^{\circledR}$ system, respectively. The strain rate is $0.01 \mathrm{~s}^{-1}$. Thirty compression hits were applied to the specimen (fifteen along each direction) leading to a total equivalent plastic strain of about 13. The equivalent strain (total and plastic) for each hit during the process is presented in Fig. 1(b). It decreases as the number of hit increases since a small quantity of matter is ejected toward the edges of the sample at each compression. The maximum von Mises stress for the first hit reaches about $1250 \mathrm{MPa}$ while it increases up to almost $1800 \mathrm{MPa}$ for the following hits, due to the strain hardening.

In order to investigate the nano-oxides distribution throughout the thermomechanical treatment, energy filtered transmission electron microscopy (EFTEM) was used to perform electron energy loss spectroscopy (EELS) mapping using a TEM JEOL 2100 operating at $200 \mathrm{kV}$.
The jump ratio images were acquired in the low-loss regions using the two-windows method. For the Fe M edge jump ratio image, the preedge energy is $48 \mathrm{eV}$ while the post edge energy is $64 \mathrm{eV}$. For the $\mathrm{Cr} \mathrm{M}$ edge jump ratio image, the pre-edge energy is $36 \mathrm{eV}$ while the post edge energy is $52 \mathrm{eV}$. The slit width was $8 \mathrm{eV}$ for all the jump ratio images.

In addition, samples were analyzed by Small Angle Neutron Scattering (SANS) due to the ability of this technique to detect the smallest precipitates $(<2 \mathrm{~nm})$ and to have a considerably higher analyzed volume compared to TEM. SANS experiments were performed at Léon Brillouin laboratory (CEA-CNRS), using the PAXY spectrometer, in the same conditions as those reported by Mathon et al. [30]. It should be noted that acquisition conditions enable to detect particles with size ranging from 0.5 to $25 \mathrm{~nm}$, namely that the SANS signal results essentially from the contribution of the Y-Ti-O nano-oxides. To fit the data, spherical particles are considered and two Gaussian distributions are used to model a bimodal population, as already reported in the literature [30-32]. For more information about the SANS technique and the fitting method used, the reader is referred to [30].

\section{Results and discussion}

Fig. 2 shows the EFTEM iron jump ratio maps carried out on the samples. Thickness $e$ was measured using its relation with the mean free path of the electrons $\lambda$ in the plasmon such as $\mathrm{z}=\mathrm{e} / \lambda$ where $z$ is the scale parameter of the thickness maps. On Fig. 2, the first compression direction is normal to the observation plan. The second compression direction being orthogonal to the first one, it lies in the observation plan. In the observed areas, $\mathrm{z}$ is ranging from 0.2 to 0.5 for every samples, allowing to perform a reliable comparison between them. One can noticed on the as-extruded material in Fig 2(a) many local iron depletions that exhibit a near-spherical shape and are about 5-10 nm large. The insets on Fig 2(a) clearly show that these local iron depletions are correlated with titanium enrichments. These local modifications of the chemical composition directly indicate the presence of the well-reported Y-Ti-O nano-oxides. It can be mentioned that EFTEM analyses (not shown here) were also performed on a sample after a single compression of $\varepsilon=0.7$ and Y-Ti-O nano-oxides were still visible.

After SPD (Fig. 2(b)), it is much more difficult to distinguish the presence of Y-Ti-O particles and only two were observed, as shown in the 

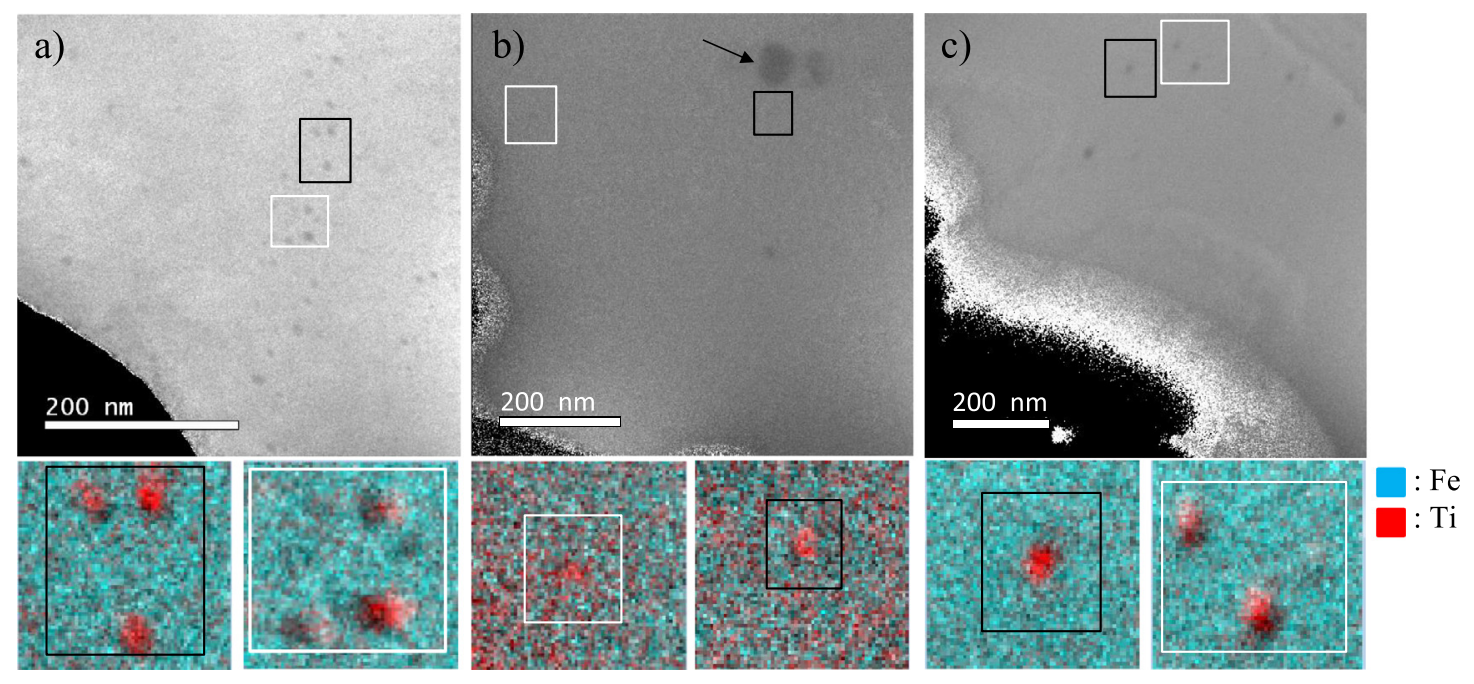

Fig. 2. EFTEM Fe jump ratio maps in (a) as-extruded material, (b) after SPD and (c) after subsequent annealing $1 \mathrm{~h}$ at $1150^{\circ} \mathrm{C}$. Insets below each maps shows the superimposition of $\mathrm{Fe}$ and $\mathrm{Ti}$ jump ratio maps.
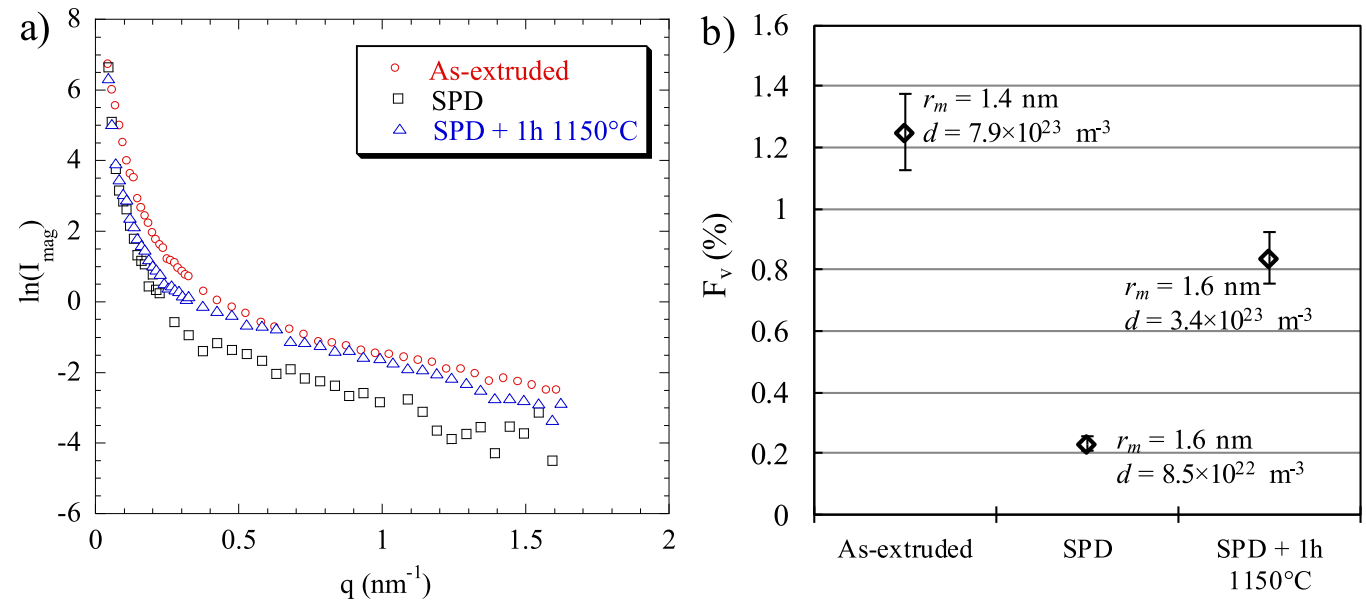

Fig. 3. (a) Scattered magnetic intensity obtained from SANS and (b) volume fraction with associated average precipitates radii and density for the three samples investigated.

insets. The larger iron depletion in the top right corner (black arrow) does not show titanium enrichment and is more likely a chromium carbide. In order to ensure the reproducibility of this result, ten other areas were analyzed in the SPD sample, and no particles were detected. It should be noted that the remaining particles after SPD are still roughly spherical (insets in Fig. 2(b)), meaning that the morphology does not seem to be impacted by the deformation process. This stands out from other studies $[29,33]$ where the morphology of the oxides is affected by the deformation process. This can be explained by the deformation path applied in the present study, which consist in two orthogonal compression directions associated with a plane strain state that does not allow the material to flow in the third direction. After annealing $1 \mathrm{~h}$ at $1150^{\circ} \mathrm{C}$ (Fig. 1(c)), iron depletions and titanium enrichments are visible again, although their number appears to be lower than in the as-extruded sample. These observations highlight the effect of SPD on nano-particles: the huge amount of plastic strain introduced by the deformation process is responsible for their dissolution. Then, when annealing at high temperature, supersaturation of solute elements $(\mathrm{Y}, \mathrm{Ti}$ and $\mathrm{O})$ in the matrix leads to the precipitation of new nano-oxides.

To support the aforementioned observations and statements at a much larger scale, SANS experiments were carried out. Fig. 3(a) shows the magnetic scattered intensity as a function of the norm of the neu- trons scattering vector $q$ obtained for the different samples. The smaller the nano-particles, the higher the norm of the scattering vector [30]. In Fig. 3(b), the volume fraction of nano-particles measured in the different states is presented, with the associated mean radius $r_{m}$ of the distribution and density $d$. Here, the influence of SPD and subsequent heat treatments on the nanoparticles distribution is emphasized. After SPD, the scattered magnetic intensity on Fig 3(a) (black curve) is clearly shifted toward lower values compared to the as-extruded state (red curve). The more important dispersion at high values of $q$ for the SPD sample can be explained by the higher contribution of the noise to the total signal, since there are much less precipitates. This could also indicates that the smaller nano-oxides ( $q$ higher than $1 \mathrm{~nm}^{-1}$ ) preferentially dissolve compared to the larger ones. Fitting the magnetic intensity curves enables to obtain the characteristics of the distribution, which are presented in Fig. 3(b). It can be noticed an important decrease of the volume fraction and density after SPD compared to the as-extruded material. The volume fraction is reduced from $1.2 \%$ to $0.2 \%$ and the density drops by one order of magnitude.

After annealing $1 \mathrm{~h}$ at $1150^{\circ} \mathrm{C}$, the scattered magnetic intensity in Fig. 3(a) is notably higher than after SPD and exhibits the same trend as that of the initial as-extruded state. The volume fraction increases from $0.2 \%$ after SPD to $0.8 \%$ after annealing at $1150{ }^{\circ} \mathrm{C}$ and the density reaches $3.4 \times 10^{23} \mathrm{~m}^{-3}$. The mean radius of precipitates does not 
vary, which means that Y-Ti-O particles re-precipitate with a nanometric size.

Consequently, SANS experiments and EFTEM analyses are in a good agreement and it can be concluded that most of the Y-Ti-O nano-oxides are dissolved by plastic deformation, and re-precipitate after annealing, with their initial nanometric size. This phenomenon appears to be similar to the dissolution of $\mathrm{Y}_{2} \mathrm{O}_{3}$ particles during mechanical alloying $[10,34]$ and the further precipitation of nano-oxides during hot consolidation of ODS materials. However, strain-induced dissolution of the much more stable and smaller Y-Ti-O oxides in a consolidated ODS steel was never clearly observed, although Aydogan et al. [35] recently suspected it due to a change of the precipitates morphology before and after uniaxial compression and recrystallization.

In the following, several aspects concerning thermodynamic and/or mechanical features are evoked to account for this singular dissolution of the Y-Ti-O oxides. Nonetheless, it should be mentioned that the identification of a specific mechanism to explain this phenomenon is beyond the scope of this paper.

Thermodynamic considerations are found in the literature to take into account the dissolution of second-phase particles. The heavy plastic deformation introduced leads to an out-of-equilibrium matrix and the creation of many boundaries, interstitials and vacancies. This state could provoked the dissolution of the nano-oxydes. During the milling of ODS powder, Kimura et al. [9] proposed that grain boundaries with amorphous areas in their vicinity would act as sinks for yttrium and oxygen atoms ejected from the $\mathrm{Y}_{2} \mathrm{O}_{3}$ particles due to successive crushing steps. The interfacial energy gradually increases as the size of the precipitate decreases, until it reaches a critical radius and dissolves completely. Strain-induced dissolution is also reported in heavily drawn pearlitic steels. Several authors $[3,36]$ consider that the cementite dissolution results from the transfer of carbon atoms from $\mathrm{Fe}_{3} \mathrm{C}$ to ferrite or grain boundaries due to a higher binding energy between carbon and dislocations in ferrite. In another system (Cu-Fe alloy), Sauvage et al. [37] showed that the large amount of vacancies introduced by plastic deformation strongly enhance the inter-diffusion and the mechanical alloying even though the solubility of $\mathrm{Fe}$ in $\mathrm{Cu}$ is normally very low. Similar thermodynamic analyses of relative phase stability after mechanical alloying could be proposed to explain the dissolution of $\mathrm{Y}$-Ti-O nanoclusters.

In the meantime, mechanical aspects are relative to the interactions between dislocations and precipitates. Two mechanisms are usually considered for such interactions, namely the Orowan by-passing mechanism or the shearing of precipitates by the dislocations. The Orowan bypassing mechanism is generally observed on large and non-deformable particles, such as $\theta\left(\mathrm{Al}_{2} \mathrm{Cu}\right)$ phase in aluminum alloys or intermetallic phases, that dislocations cannot cross. The dislocation bows over the particles and releases, leaving dislocation loops around the precipitates. Particles that usually undergo by-passing are very difficult to dissolve by plastic deformation.

The shearing mechanism is likely to occur in the case of deformable and coherent particles: dislocations go through the particles considering continuous slip planes at the particle-matrix interface. During this mechanism, atoms are progressively ejected from the particles by successive shearing and put back into solution [8]. This was observed experimentally on Guinier-Preston (GP) zones and on coherent $\theta$ " and $\theta$ ' precipitates in Al-Cu alloys [6-8]. Moreover, Jiao et al. [2] mentioned about $\mathrm{Ni} / \mathrm{Si}$-rich radiation-induced clusters that the shearing of a precipitate by dislocations is very likely to increase its free energy as well as the area of its interface and so favor its dissolution. Experimentally, none of the above mechanisms (by-passing or shearing) has been observed on YTi-O nanoparticles so far, even under monotonic loading. Despite their coherency with the matrix and their nanometric size, it was computed by Takahashi et al. [38] that the critical resolved shear stress (CRSS) necessary to shear the ODS precipitates exceeds $20 \mathrm{GPa}$, which is much higher than the maximum stress reached under monotonic loading. On this basis, Orowan by-passing is rather considered in the literature although no residual dislocation loops around the nanoparticles were distinctly found either. It is also likely that from a certain number of compression hits, the accumulated strain hardening is high enough for the CRSS value to be reached around the nano-oxides, activating the shearing mechanism. A similar mechanism was observed by Brechet and Louchet [39] on coherent $\delta$ ' precipitates in an Al-Li alloy after fatigue test where Orowan loops finally shear the precipitates when the local stress become higher than a critical value. The authors named this phenomenon "delayed-shearing".

Thus, dissolution of Y-Ti-O nano-oxides by SPD could results from a combination of both mechanical and thermodynamic aspects. These results also lead to questions about the dissolution mechanisms of oxides observed during the Mechanical Alloying (MA). During this step, it is noticed that the oxides, mixed with the metal powders, are completely dissolved. If we consider that the mechanisms of dissolution during the Mechanical Alloying (MA) are the same as those observed in this study by SPD, it suggests that during the MA, the oxides (which can be several microns large at the start) are fractured, finely dispersed and then completely embedded in the matrix. Then, the same phenomena as those seen in this study could lead to the complete dissolution of the oxides due to the significant plastic deformation of the metal powders.

Further experiments would be necessary to clarify the nanooxides/dislocations interactions throughout the deformation process. The amount of plastic strain at which particles start dissolving also deserves to be investigated. Nevertheless, this study shows that the straininduced dissolution observed so far in the literature in precipitates that can be thermally dissolved ( $\theta^{\prime \prime}, \theta^{\prime}, \mathrm{Fe}_{3} \mathrm{C}, \varepsilon$-Cu...) can be observed also with highly stable nanoparticles that remain at equilibrium above the melting point of the matrix. Moreover, the ability to recover the initial size and density after annealing appears noteworthy, particularly to manage the dissolution/precipitation sequence during the manufacturing route of ODS materials.

\section{Acknowledgment}

The authors would like to warmly thank Dr. Denis Sornin (CEA/DEN/DMN/SRMA/LTMEX) for his help in this study and the supply of the material.

\section{References}

[1] T. Tsuchiyama, S. Yamamoto, S. Hata, M. Murayama, S. Morooka, D. Akama S. Takaki, Acta Mater. 113 (2016) 48-55.

[2] Z. Jiao, M.D. McMurtrey, G.S. Was, Scr. Mater. 65 (2011) 159-162.

[3] V.G. Gavriljuk, Mater. Sci. Eng. A 345 (2003) 81-89.

[4] X. Sauvage, M.Y. Murashkin, B.B. Straumal, E.V. Bobruk, R.Z. Valiev, Adv. Eng. Mater. 17 (2015) 1821-1827.

[5] B.B. Straumal, A.R. Kilmametov, Y. Ivanisenko, A.S. Gornakova, A.A. Mazilkin, M..J. Kriegel, O.B. Fabrichnaya, B. Baretzky, H. Hahn, Adv. Eng. Mater. 17 (2015) $1835-1841$

[6] W. Huang, Z. Liu, L. Xia, P. Xia, S. Zeng, Mater. Sci. Eng. A 556 (2012) 801-806.

[7] Z. Liu, S. Bai, X. Zhou, Y. Gu, Mater. Sci. Eng. A 528 (2011) 2217-2222.

[8] C.R. Hutchinson, P.T. Loo, T.J. Bastow, A.J. Hill, J. da Costa Teixeira, Acta Mater. 57 (2009) 5645-5653.

[9] Y. Kimura, S. Takaki, S. Suejima, R. Uemori, H. Tamehiro, ISIJ Int. 39 (1999) 176-182.

[10] M. Ratti, D. Leuvrey, M.H. Mathon, Y. de Carlan, J. Nucl. Mater. 386 (2009) 540-543 -388 .

[11] C.L. Chen, Y.M. Dong, Mater. Sci. Eng. A 528 (2011) 8374-8380.

[12] Z. Oksiuta, N. Baluc, Nucl. Fus. 49 (2009) 55003.

[13] L. Toualbi, M. Ratti, G. André, F. Onimus, Y. De Carlan, J. Nucl. Mater. 417 (2011) 225-228.

[14] M.-L. Lescoat, J. Ribis, A. Gentils, O. Kaïtasov, Y. De Carlan, A. Legris, J. Nucl. Mater. 428 (2012) 176-182.

[15] M.J. Alinger, G.R. Odette, D.T. Hoelzer, J. Nucl. Mater. 333 (2004) 382-386.

[16] J. Ribis, Y. De Carlan, Acta Mater. 60 (2012) 238-252.

[17] J. Ribis, M. Lescoat, S.Y. Zhong, M. Mathon, Y. De Carlan, J. Nucl. Mater 442 (2013) $101-105$.

[18] X. Boulnat, M. Perez, D. Fabrègue, S. Cazottes, Y. De Carlan, Acta Mater. 107 (2016) 390-403.

[19] Y. Jiang, J.R. Smith, G. Robert Odette, Acta Mater. 58 (2010) 1536-1543.

[20] Y. Wu, J. Ciston, S. Kräemer, N. Bailey, G.R. Odette, P. Hosemann, Acta Mater. 111 (2016) 108-115. 
[21] S.Y. Zhong, J. Ribis, N. Lochet, Y. de Carlan, V. Klosek, M.H. Mathon, J. Nucl. Mater. 455 (2014) 618-623.

[22] H. Sakasegawa, L. Chaffron, F. Legendre, L. Boulanger, T. Cozzika, M. Brocq, Y. de Carlan, J. Nucl. Mater. 384 (2009) 115-118.

[23] M. Lescoat, J. Ribis, Y. Chen, E.A. Marquis, E. Bordas, P. Trocellier, Acta Mater. 78 (2014) 328-340

[24] S. Ukai, T. Okuda, M. Fujiwara, T. Kobayashi, S. Mizuta, H. Nakashima, J. Nucl. Sci. Technol. 39 (2012) 872-879.

[25] M.K. Miller, D.T. Hoelzer, E.A. Kenik, K.F. Russell, J. Nucl. Mater. 329 (2004) 338-341 -333.

[26] M.J. Alinger, G.R. Odette, D.T. Hoelzer, Acta Mater. 57 (2009) 392-406.

[27] M. Dade, J. Malaplate, J. Garnier, F. De Geuser, N. Lochet, A. Deschamps, J. Nucl. Mater. 472 (2016) 143-152.

[28] J. Shen, H. Yang, Y. Li, S. Kano, Y. Matsukawa, Y. Staoh, H. Abe, J. Alloy. Compd. 695 (2017) 1946-1955.

[29] Z. Zhang, W. Pantleon, Acta Mater. 149 (2018) 235-247.

[30] M.H. Mathon, M. Perrut, S.Y. Zhong, Y. de Carlan, J. Nucl. Mater. 428 (2012) $147-153$.
[31] S.Y. Zhong, J. Ribis, T. Baudin, N. Lochet, Y. de Carlan, V. Klosek, M.H. Mathon, J. Nucl. Mater. 452 (2014) 359-363.

[32] P. Olier, J. Malaplate, M.H. Mathon, D. Nunes, D. Hamon, L. Toualbi, Y. de Carlan, L. Chaffron, J. Nucl. Mater. 428 (2015) 40-46.

[33] M. Song, C. Sun, J. Jang, C.H. Han, T.K. Kim, K.T. Hartwig, X. Zhang, J. Alloy. Compd. 577 (2013) 247-256.

[34] T. Okuda, M. Fujiwara, J. Mater, Sci. Lett. 14 (1995) 1600-1603.

[35] E. Aydogan, O. El-Atwani, S. Takajo, S.C. Vogel, S.A. Maloy, Acta Mater. 148 (2018) $467-481$.

[36] A. Lamontagne, V. Massardier, X. Kléber, X. Sauvage, D. Mari, Mater. Sci. Eng. A 644 (2015) 105-113.

[37] X. Sauvage, F. Wetscher, P. Pareige, Acta Mater. 53 (2005) 2127-2135.

[38] A. Takahashi, Z. Chen, N. Ghoniem, N. Kioussis, J. Nucl. Mater. 417 (2011) 1098-1101.

[39] Y. Brechet, F. Louchet, Acta Metall. 37 (1989) 2469-2473. 